\title{
Workplace physical activity interventions and moderate-to-vigorous intensity physical activity levels among working-age women: a systematic review protocol
}

Jennifer L Reed ${ }^{1 *}$, Stephanie A Prince ${ }^{1}$, Christie A Cole ${ }^{1}$, J George Fodor ${ }^{1}$, Swapnil Hiremath², Kerri-Anne Mullen ${ }^{1}$, Heather E Tulloch', Erica Wright ${ }^{3}$ and Robert D Reid ${ }^{1}$

\begin{abstract}
Background: The rapid pace of modern life requires working-age women to juggle occupational, family and social demands. This modern lifestyle has been shown to have a detrimental effect on health, often associated with increased smoking and alcohol consumption, depression and cardiovascular disease risk factors. Despite the proven benefits of regular moderate-to-vigorous intensity physical activity (MVPA), few are meeting the current physical activity (PA) recommendations of 150 min of MVPA/week. It is important that appropriate and effective behavioural interventions targeting PA are developed and identified to improve the MVPA levels of working-age women. As these women spend a substantial proportion of their waking hours at work, workplaces may be an opportune, efficient and relatively controlled setting to implement programmes and strategies to target PA in an effort to improve MVPA levels and impact cardiometabolic health. The purposes of this systematic review are to compare the effectiveness of individual-level workplace interventions for increasing MVPA levels in working-age women in high-income/developed countries and examine the effectiveness of these interventions for improving the known beneficial health sequelae of MVPA.
\end{abstract}

Methods/Design: Eight electronic databases will be searched to identify all prospective cohort and experimental studies that examine the impact of individual-level workplace interventions for increasing MVPA levels among working-age (mean age 18-65 years) women from high-income/developed countries. Grey literature including theses, dissertations and government reports will also be included. Study quality will be assessed using a modified Downs and Black checklist, and risk of bias will be assessed within and across all included studies using the Cochrane's risk of bias tool and Grades of Recommendation, Assessment, Development and Evaluation approach. Meta-analyses will be conducted where possible among studies with sufficient homogeneity.

Discussion: This review will determine the effectiveness of individual-level workplace interventions for increasing MVPA levels in working-age women in high-income/developed countries, and form a current, rigorous and reliable research base for policy makers and stakeholders to support the development and implementation of effective workplace interventions that increase MVPA levels in this population.

Systematic review registration: PROSPERO CRD42014009704

Keywords: Motor activity, Women, Workplace, Occupation, Exercise, Physical activity, Systematic review

\footnotetext{
*Correspondence: jreed@ottawaheart.ca

'Division of Prevention and Rehabilitation, University of Ottawa Heart

Institute, 40 Ruskin Street, Ottawa, ON K1Y 4W7, Canada

Full list of author information is available at the end of the article
} 


\section{Background}

The rapid pace of modern life requires working-age women to juggle occupational, family and social demands. On most days of the week, working-age women in North America which constitute $48 \%$ of the total workforce spend a substantial proportion of their waking hours at work, while also contributing more to unpaid work (e.g. cooking, cleaning, child care, gardening) as compared to their male counterparts [1,2]. Further, women represent the largest proportion (79\%) of single-parent families [3] and earn $22 \%$ to $33 \%$ less, on average, than males for equivalent full-time paid work [4-6]. Among lower income families, the need to work overtime or more than one job is also quite common [7], which leaves little time for women to prioritize their health. Indeed, it has been shown that women who work long hours exhibit higher rates of smoking and alcohol consumption and are more likely to be depressed [8].

According to the recent Canadian Health Measures Survey (CHMS) and National Health and Nutrition Examination Survey (NHANES) data, 28\% to 31\% of workingage women were classified as overweight, and $24 \%$ to $36 \%$ were classified as obese, respectively $[9,10]$. An alarming proportion of working-age women in North America experience risk factors for cardiovascular diseases [11,12], the leading cause of death in North America, including: high blood pressure (estimates of 19\%-32\%) [13,14], high cholesterol (estimates of $11 \%-25 \%)$ [15,16] and diabetes (estimates of $7 \%-11 \%$ ) $[17,18]$. Despite this, most women lack knowledge of cardiovascular disease risk factors, and substantial proportions (80\%) are unaware of their own risk status [19].

Physical activity (PA) is an important modifiable health behaviour. Irrefutable evidence demonstrates the effectiveness of regular PA in the prevention of several chronic diseases including, but not limited to cardiovascular disease, high blood pressure, high cholesterol, diabetes, certain cancers and premature death [20-23]. The dose-response relationship is such that greater health benefits are achieved in proportion to increasing levels, within physiological limits, of PA [20-22]. According to the World Health Organization (WHO), adults should accumulate at least $150 \mathrm{~min}$ of moderate-to-vigorous intensity aerobic PA (MVPA) each week [24]. Examples of MVPA include brisk walking, running, cycling, lifting heavier loads, swimming and competitive sports. Most household activities are not vigorous enough to meet current MVPA recommendations [1,25]. Unfortunately, despite the proven benefits of regular MVPA, very few $(3 \%-14 \%)$ working-age women in North American, and less than the number of working-age men $(4 \%-17 \%)$, are meeting current MVPA recommendations [23,26]. Lack of time is one of the most commonly cited barriers to regular PA participation [27].
It is important that appropriate and effective behavioural interventions targeting PA are developed and identified to improve the MVPA levels of working-age women [28]. As this population spends a substantial proportion of their waking hours at work, workplaces may be an opportune, efficient and relatively controlled setting to implement programmes and strategies to target PA in an effort to improve MVPA levels and subsequently impact cardiometabolic health. Since employees with poor health and those with unhealthy lifestyles and chronic health conditions are less productive at work and take more sick leave [29-31], the potential to reduce absenteeism rates and healthcare costs may represent a strong incentive for the implementation of workplace programmes to increase MVPA levels to employers.

Although previous reviews have demonstrated the beneficial effects of workplace PA interventions on PA levels (i.e. minutes/hours per week), fitness, nutritional practices, body weight, psychosocial factors, work performance, health risks and healthcare cost outcomes among working-age adults [32-35], few have evaluated the impact on levels of MVPA [34,35] and none have focused on working-age women from high-income Organization for Economic Co-operation and Development (OECD) countries [36] which exhibit poor adherence rates $(\leq 50 \%)$ to current PA recommendations [23,37]. The main objective of the proposed systematic review will be to compare the effectiveness of individual-level workplace interventions for increasing MVPA levels in working-age women in high-income/developed countries. The secondary objective will be to examine the effectiveness of these interventions for improving the known beneficial health sequelae of MVPA (e.g. weight, body mass index (BMI), body composition, waist circumference, blood pressure, blood serum lipids and glucose concentrations).

\section{Methods/Design}

\section{Study design}

A systematic review and meta-analysis will be performed to identify individual-level workplace interventions to increase MVPA levels in working-age women in high-income/developed countries. The systematic review will adhere to the reporting guidelines of the Preferred Reporting Items for Systematic Reviews and Meta-Analyses (PRISMA) statement [38] and will meet the items outlined in A Measurement Tool to Assess Systematic Reviews (AMSTAR) checklist $[39,40]$.

\section{Study registration}

This systematic review is registered with PROSPERO (registration number: CRD42014009704; www.crd.york. ac.uk/PROSPERO). 


\section{Types of participants}

Studies will be included if the sample is largely comprised of working-age women $(\geq 80 \%$ women in the sample or where female data can be extracted) from high-income/ developed countries, defined according to OECD, with a mean age between 18 and 65 years.

\section{Types of exposures}

All studies must contain an intervention component delivered in the workplace that is designed to increase MVPA levels. The interventions may include, but are not limited to: group aerobics classes; team sports; and walking, running or stair initiatives. The delivery of the interventions may be single- or multi-modal.

\section{Types of comparators}

Since this systematic review will include all prospective cohort and experimental studies (randomized controlled trials (RCTs), pre-post design, quasi-experimental) studies that examine the impact of individual-level workplace interventions on increasing MVPA levels among workingage women, control groups will be used, when available, to compare effects. No restrictions will be placed on the control groups (e.g. no PA intervention, low intensity PA intervention).

\section{Types of outcomes}

The primary outcome will be change in minutes per day of MVPA. MVPA is defined as a behaviour with an energy expenditure $\geq 3$ metabolic equivalents (METs), $\geq 40 \%$ of $\mathrm{VO}_{2}$ reserve, $\geq 64 \%$ of peak heart rate, $\geq 12$ rating of perceived exertion or $>100$ steps per minute [25,41-44]. Measures of time (e.g. minutes per day) spent engaging in MVPA and where possible, a measure of variance around this outcome (e.g. standard error, 95\% confidence intervals) will be extracted from all eligible and included studies regardless of the unit or method of MVPA measurement. MVPA can be either objectively measured (e.g. indirect calorimetry, accelerometers, pedometers, activity monitors) or self-reported (e.g. questionnaire, journal or log). Further, MVPA can be described using a composite measure of total time spent in MVPA or separately for moderate and vigorous intensities. Secondary outcomes including potential and known beneficial health sequelae of MVPA (e.g. weight, BMI, body composition, waist circumference, blood pressure, blood serum lipids, glucose concentrations) [20-22] will be extracted.

\section{Types of studies}

We will include all prospective cohort and experimental (RCTs, pre-post design, quasi-experimental) studies that examine the impact of individual-level workplace interventions on increasing MVPA levels among working-age women from high-income/developed countries. Only articles available in English and French will be included as the authors are proficient in these languages. If there is an adequate number of RCTs, a summary of this evidence and the confidence in this evidence using the Grades of Recommendation, Assessment, Development and Evaluation (GRADE) approach [45] will be provided to increase internal validity of the systematic review. RCTs receive the highest grade with this approach.

\section{Search methods for the identification of studies}

A comprehensive search strategy was designed in collaboration with a research librarian (EW), peer-reviewed by a second research librarian (SD), and includes a search of eight electronic databases: Ovid MEDLINE ${ }^{\oplus}$ In-Process and Other Non-Indexed Citations (1946 to present); EBM Reviews-Cochrane Database of Systematic Reviews (2005 to July 2014), EBM Reviews-Cochrane Central Register of Controlled Trials (1991 to present); EMBASE Classic + (1947 to present); CINAHL (1981 to present); Ovid PsycINFO (1806 to present); SPORTDiscus (1949 to present) and Dissertations and Theses (1980 to present). The strategy is illustrated using the MEDLINE search as an example (Table 1) and will be modified according to the indexing systems of the other databases. Grey literature (non-peer-reviewed works) that meets the inclusion criteria will be obtained including published lists of theses and dissertations, government reports and unpublished data and manuscripts (provided by original authors). Government reports will be searched using the Google search engine and a combination of key text words. Unpublished data and manuscripts will be solicited from original authors of studies that report on collecting MVPA. The bibliographies of all studies selected for the review will be examined to identify further studies as will those of previous reviews. The Google search engine will be used to identify studies that are published in non-indexed journals.

\section{Selection of studies}

Articles will be imported into Microsoft Excel (Microsoft Canada Inc. Mississauga, ON, Canada), and all duplicates will be removed; only the most relevant article per data source/analysis will be retained. Two independent reviewers (JLR, CAC) will screen the titles and abstracts of all articles to identify potentially relevant articles. Full texts of each potentially relevant article identified by either reviewer during the title and abstract screening phase will be reviewed to determine whether the title and abstract screening inclusion criteria are met. The full texts of all potential articles that meet the inclusion criteria will be obtained and reviewed. Two independent reviewers will screen the full texts for inclusion (JLR, CAC). Any disagreements between the reviewers will be resolved by consensus and or discussion with a third reviewer (SAP). Intra-class correlations will be calculated 
Table 1 Sample MEDLINE search strategy

\begin{tabular}{ll}
\hline Search terms \\
\hline Workplace terms \\
1 & Workplace/(13603) \\
2 & workplace*.tw. (24754) \\
3 & worksite*.tw. (2512) $^{*}$ (work* adj (place* or site* or location* or setting*)).tw. (5663) $^{*}$ \\
5 & "place of work".tw. (656) \\
6 & (employer* or employee* or worker*).tw. (158577) \\
7 & (office adj2 work*).tw. (1799) \\
8 & Occupational Health Services/(9650) \\
9 & Occupational Health/(25082) \\
10 & or/1-9 (201628)
\end{tabular}

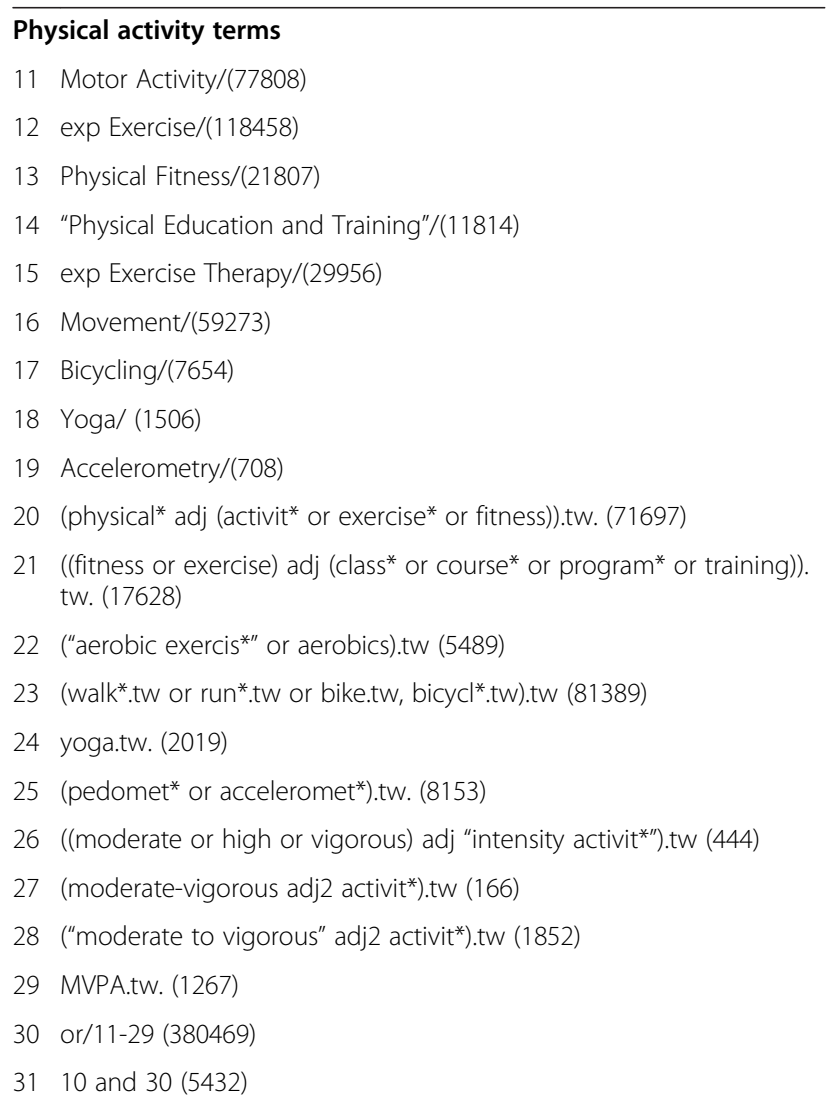

Table 1 Sample MEDLINE search strategy (Continued)

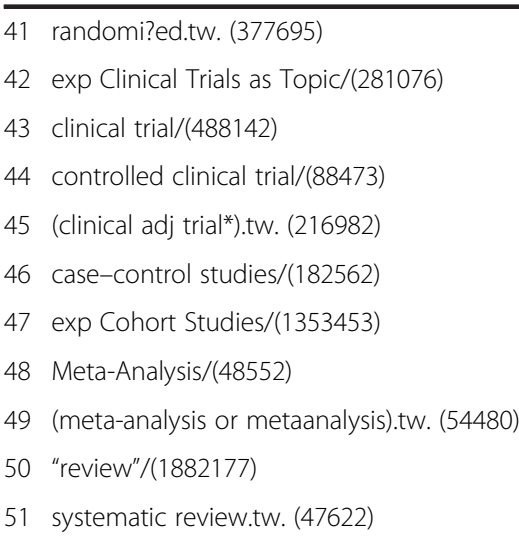

to assess agreement between the reviewers. Reviewers will not be blinded to the authors or journals when screening articles.

\section{Data collection}

Prior to data extraction, a data extraction form will be created and tested by the research team using a subset of the included studies. The extraction form will be modified based on feedback from the research team to improve its usability and ensure that complete and pertinent data is obtained. Standardized data abstraction forms including quality assessments will be completed by both reviewers (JLR and CAC). Any disagreements will be resolved by consensus and or discussion with a third reviewer (SAP or RDR). Reviewers will not be blinded to the authors or journals when extracting data.

From each prospective cohort and experimental study, the following data will be extracted: publication details (authors, year, country of study), participants' characteristics (age range, mean age, sex distribution, chronic diseases, health states, population, setting), sample size, study design (RCT, pre-post, quasi-experimental), time points when data were collected (e.g. 3 weeks, 4 months), length of follow-up, intervention details, description of control, usual care or wait list-control group, information regarding blinding and randomization techniques, MVPA measurement method and whether self-report or objective tools were used, MVPA units of measurement, statistical analyses methods (i.e. $t$-tests, linear modeling), effect of the intervention on MVPA (effect size, 95\% CI, standard mean error or deviation) and effect of intervention on known beneficial health sequelae of MVPA (weight, BMI, body composition, waist circumference, blood pressure, blood serum lipids, glucose concentrations) [20-22]. In cases where several publications report the same results 
from the same data source, only one article per data source/analysis will be retained to avoid double counting. If an investigator uses a measure that has the potential to capture MVPA (e.g. FITT log, accelerometers) but does not report on these outcomes in the manuscript, or if a paper reports on a study protocol, the authors will be contacted to determine whether the MVPA results can be obtained; other missing data to determine inclusion criteria (e.g. study design, age distribution, sex distribution) will also be obtained. A maximum of two e-mail or phone call attempts will be made to contact the corresponding author of these articles to obtain additional data.

\section{Quality and risk of bias within studies}

The Downs and Black checklist will be used to assess the quality and risk of bias of the individual studies [46]. The checklist contains 27 items, with a maximum possible score of 32 points [46]. We will simplify the scoring of item 27 from a five-point range to a binary system, granting one point (1) for adequate power calculations or no points (0) if power was not adequately addressed. The maximum possible score for the modified checklist will be 28 points with higher scores indicating superior quality. The quality of the individual studies will be rated by reviewer CAC and verified by reviewer JLR. The quality scores will be used for performing subgroup analyses (high-quality vs. lowquality). The Cochrane Collaboration's tool will be used to assess risk of bias for each RCT. Items included in Cochrane's risk of bias assessment include: sequence generation (randomization); allocation concealment; blinding of participants, personnel and investigator; incomplete data (e.g. losses to follow-up, intention-to-treat analysis); selective outcome reporting; and other possible sources of bias. The risk of bias assessment will be carried out by two independent assessors (JLR and CAC); any disagreements between assessors will be resolved by consensus and or through discussion with a third reviewer (SAP).

\section{Quality of the evidence}

The quality of the evidence for the RCTs will be assessed as high, moderate, low or very low using the GRADE approach [45]. With the GRADE approach, the highest quality rating is for RCT evidence. In addition to study design, the quality of evidence will be rated upon possible risk of bias, imprecision, heterogeneity, indirectness or suspicion of publication bias. Risk of bias for the RCTs will be assessed using Review Manager (RevMan) 5.3.3 (The Nordic Cochrane Centre, The Cochrane Collaboration, 2012) [47] and then imported into GRADEprofiler (GRADEpro) Version 3.6.1 [48] to create a summary of findings table and rate the quality of the evidence using the GRADE approach.

\section{Analysis}

Forest plots and meta-analyses will be created using RevMan 5.3.3 to synthesize the measures of effect (e.g. mean differences) and 95\% confidence intervals for each intervention on MVPA. Forest plots and meta-analyses will only be performed when the included studies are sufficiently homogenous in terms of study design, participants, interventions and outcomes to provide a meaningful summary measures. A random-effects meta-analysis will be used as effect sizes are likely to be similar, but not identical across all studies. Inverse variance methods will be used for continuous data and DerSimonian Laird methods for dichotomous data. Heterogeneity will be assessed using the $I^{2}$ statistic with values above $75 \%$ and $p<0.10$ used to indicate high heterogeneity across studies [49]. If high heterogeneity is found, a meta-analysis will not be performed. A funnel plot of the included studies' estimates of effect will be used to assess the presence of publication bias. Funnel plots will only be performed if ten or more studies are included. The plots will be assessed both visually and by using Egger's test, with $p<0.10$ used to indicate the presence of a significant publication bias [50].

\section{Subgroup analyses}

Several subgroup analyses will be performed if sufficient data are available. These analyses will examine differences between: age (e.g. 18-24 years vs. 25-44 years vs. 45-65 years); number of children; education (e.g. high school vs. post-secondary vs. graduate); marital status (e.g. married vs. unmarried); occupation (e.g. active vs. sedentary jobs); worksite (e.g. office vs. hospital); working status (e.g. casual, part-time $[<37.5 \mathrm{~h} /$ week] vs. full-time $[37.5-40 \mathrm{~h} /$ week] vs. excessive overtime [ $>40 \mathrm{~h} /$ week]); income; selfreported and objectively measured MVPA; intervention focus (e.g. walking vs. aerobic classes vs. team sports vs. exercise and diet programmes vs. gym membership), intervention mode (e.g. web-based vs. paper-based); intervention delivery (e.g. single- vs. multi-modal); study design (e.g. control group vs. no control group, randomized vs. non-randomized controlled trial); control groups (e.g. no PA intervention vs. low intensity PA intervention) and impact on known beneficial health sequelae of MVPA (e.g. weight vs. BMI vs. body composition vs. waist circumference vs. blood pressure vs. blood serum lipids vs. glucose concentrations). Subgroup analyses will be used to explore heterogeneity, in addition to any clinical interest in the differences between groups.

\section{Discussion}

This systematic review will be the first, to our knowledge, to determine the effectiveness of individual-level workplace interventions for increasing MVPA levels in working-age women in high-income/developed countries. The findings from this review will provide a current, rigorous and 
reliable research base for policy makers and stakeholders to support the design and implementation of effective workplace interventions that increase MVPA levels in working-age women in high-income/developed countries that likely have poor health and accumulate low MVPA levels. The findings from this review will be disseminated for scientific peer-reviewed open access publication, as well as conference presentation and proceedings. The review authors will also disseminate the findings to health researchers and academic institutions through national and international seminars and workshops.

\section{Abbreviations}

MVPA: Moderate-to-vigorous intensity physical activity; PA: Physical activity; CHMS: Canadian Health Measures Survey; NHANES: National Health and Nutrition Examination Survey; WHO: World Health Organization; OECD: Organization for Economic Co-operation and Development; BMI: Body mass index; PRISMA: Preferred Reporting Items for Systematic Reviews and Meta-Analyses; AMSTAR: A Measurement Tool to Assess Systematic Reviews; RCT: Randomized controlled trials; METS: Metabolic equivalents; GRADE: Grades of Recommendation, Assessment, Development and Evaluation.

\section{Competing interests}

The authors declare that they have no competing interests.

\section{Authors' contributions}

JLR and RDR conceived the idea for this study. JLR, SAP and CAC developed the methods and drafted this protocol. JGF, SH, KAM, HET and EW acted as the secondary reviewers. All authors read and approved the final manuscript and have given final approval of the article to be published.

\section{Acknowledgements}

This work was supported by the Ottawa Region for Advanced Cardiovascular Research Excellence (ORACLE) of the University of Ottawa Heart Institute.

\section{Author details}

'Division of Prevention and Rehabilitation, University of Ottawa Heart Institute, 40 Ruskin Street, Ottawa, ON K1Y 4W7, Canada. ${ }^{2}$ Clinical Epidemiology Program, Ottawa Hospital Research Institute, Ottawa, ON K1Y 4E9, Canada. ${ }^{3}$ Health Sciences Library, University of Ottawa, Ottawa, ON K1H $8 \mathrm{M} 5$, Canada.

Received: 7 September 2014 Accepted: 11 December 2014 Published: 19 December 2014

\section{References}

1. Miranda V: OECD social, employment and migration working papers, no. 116 cooking, caring and volunteering: unpaid work around the world. Directorate for employment, labour and social affairs. Employment, labour and social affairs committee 2011, 1:1-39.

2. Ferrao V: Paid work. Women in Canada: a gender-based statistical report. Statistics Canada (Catalogue no. 89-503-X); 2010:1-31.

3. Milan A, Bohnert N: Portrait of families and living arrangements in Canada. Families, households and marital status, 2011 census of population. Statistics Canada (Catalogue no. 98-312-X2011001); 2012:1-20.

4. Statistics Canada: Distribution of earnings, by sex, 2011 constant dollars, annual. Statistics Canada (Table 202-0101); 2011.

5. United States Census Bureau: Median earnings in the past 12 months (in 2012 inflation-adjusted dollars) of workers by sex and women's earnings as a percentage of men's earnings by selected characteristics, 2010-2012 American Community Survey 3-Year Estimates. United States Census Bureau; 2014

6. DeNavas-Walt C, Proctor BD: Income and poverty in the United States: 2013. United States Census Bureau (Current Population Reports P60-249): 2013:1-72.

7. Loprest P, Acs G, Ratcliffe C, Vinopal K: Who are low-wage workers? ASPE Research Brief, US Department of Health and Human Services; 2009:1-6.

8. Shields M: Long working hours and health. Health Reports 1999, 11(2):33-48.
9. Shields M, Tremblay M, Laviolette M, Craig C, Janssen I, Gorber S: Fitness of Canadian adults: results from the 2007-2009 Canadian Health Measures Survey. Health Reports 2010, 21:21-35.

10. Fryar CD, Carroll MD, Ogden CL: Prevalence of overweight, obesity, and extreme obesity among adults: United States, 1960-1962 through 2009-2010. National Center for Health Statistics 2014, 1-6.

11. Centers for Disease Control and Prevention: National diabetes statistics report: estimates of diabetes and its burden in the United States. Department of Health and Human Services; 2014:1-8.

12. Public Health Agency of Canada: Tracking heart disease and stroke in Canada. Public Health Agency of Canada; 2009:1-132.

13. Go A, Mozaffarian D, Roger VL, Benjamin EJ, Berry JD, Borden WB, Bravata DM, Dai S, Ford ES, Fox CS, Franco S, Fullerton HJ, Gillespie C, Hailpern SM, Heit JA, Howard VJ, Huffman MD, Kissela BM, Kittner SJ, Lackland DT, Lichtman JH, Lisabeth LD, Magid D, Marcus GM, Marelli A, Matchar DB, McGuire DK, Mohler ER, Moy CS, Mussolino ME, et al: Heart disease and stroke statistics-2013 update: a report from the American Heart Association. Circulation 2013, 127:e6-e245.

14. Wilkins K, Campbell NR, Joffres MR, McAlister FA, Nichol M, Quach S, Johansen HL, Tremblay MS: Blood pressure in Canadian adults. Health Reports 2010, 21:37-46.

15. Shay CM, Ning H, Allen NB, Carnethon MR, Chiuve SE, Greenlund KJ, Daviglus ML, Lloyd-Jones DM: Status of cardiovascular health in US adults: prevalence estimates from the National Health and Nutrition Examination Surveys (NHANES) 2003-2008. Circulation 2012, 125:45-56.

16. Statistics Canada: Cholesterol levels of adults, 2012-2013. Statistics Canada (Catalogue no. 82-625-X); 2014.

17. Centers for Disease Control and Prevention: National diabetes statistics report: estimates of diabetes and its burden in the United States, 2014 Atlanta, GA, USA: Department of Health and Human Services; 2014:1-12.

18. Public Health Agency of Canada: Diabetes in Canada: facts and figures from a public health perspective. Public Health Agency of Canada; 2011:1-126.

19. McDonnell LA, Pipe AL, Westcott C, Perron S, Younger-Lewis D, Elias N, Nooyen J, Reid RD: Perceived vs actual knowledge and risk of heart disease in women: findings from a Canadian survey on heart health awareness, attitudes, and lifestyle. Can J Cardiol 2014, 30:827-834.

20. Haskell WL, Lee IM, Pate RR, Powell KE, Blair SN, Franklin BA, Macera CA, Heath GW, Thompson PD, Bauman A: Physical activity and public health: updated recommendation for adults from the American College of Sports Medicine and the American Heart Association. Med Sci Sports Exerc 2007, 39:1423-1434.

21. Warburton DE, Nicol CW, Bredin SS: Health benefits of physical activity: the evidence. CMAJ 2006, 174:801-809.

22. Warburton DE, Charlesworth S, Ivey A, Nettlefold L, Bredin SS: A systematic review of the evidence for Canada's Physical Activity Guidelines for Adults. Int J Behav Nutr Phys Act 2010, 7:39.

23. Colley RC, Garriguet D, Janssen I, Craig CL, Clarke J, Tremblay MS: Physical activity of Canadian adults: accelerometer results from the 2007 to 2009 Canadian Health Measures Survey. Health Reports 2011, 22:7-14.

24. World Health Organization: Information sheet: global recommendations on physical activity for health. World Health Organization; 2010:1-58.

25. Ainsworth BE, Haskell WL, Whitt MC, Irwin ML, Swartz AM, Strath SJ, O'Brien WL, Bassett DR Jr, Schmitz KH, Emplaincourt PO, Jacobs DR Jr, Leon AS: Compendium of physical activities: an update of activity codes and MET intensities. Med Sci Sports Exerc 2000, 32:S498-S504.

26. Troiano RP, Berrigan D, Dodd KW, Masse LC, Tilert T, McDowell M: Physical activity in the United States measured by accelerometer. Med Sci Sports Exerc 2008, 40:181-188.

27. Trost SG, Owen N, Bauman AE, Sallis JF, Brown W: Correlates of adults' participation in physical activity: review and update. Med Sci Sports Exerc 2002, 34:1996-2001.

28. Kannel WB, Cupples LA, Ramaswami R, Stokes J 3rd, Kreger BE, Higgins M: Regional obesity and risk of cardiovascular disease; the Framingham study. J Clin Epidemiol 1991, 44:183-190.

29. Robroek SJ, van den Berg TI, Plat JF, Burdorf A: The role of obesity and lifestyle behaviours in a productive workforce. Occup Environ Med 2011, 68:134-139.

30. Alavinia SM, Molenaar D, Burdorf A: Productivity loss in the workforce: associations with health, work demands, and individual characteristics. Am J Ind Med 2009, 52:49-56.

31. van Duijvenbode DC, Hoozemans MJ, van Poppel MN, Proper KI: The relationship between overweight and obesity, and sick leave: a systematic review. Int J Obes (Lond) 2009, 33:807-816. 
32. Osilla KC, Van Busum K, Schnyer C, Larkin JW, Eibner C, Mattke S: Systematic review of the impact of worksite wellness programs. Am J Manag Care 2012, 18:e68-e81.

33. Groeneveld IF, Proper KI, van der Beek AJ, Hildebrandt VH, van Mechelen W: Lifestyle-focused interventions at the workplace to reduce the risk of cardiovascular disease-a systematic review. Scand J Work Environ Health 2010, 36:202-215.

34. Barr-Anderson DJ, AuYoung M, Whitt-Glover MC, Glenn BA, Yancey AK: Integration of short bouts of physical activity into organizational routine a systematic review of the literature. Am J Prev Med 2011, 40:76-93.

35. Castillo-Retamal M, Hinckson EA: Measuring physical activity and sedentary behaviour at work: a review. Work 2011, 40:345-357.

36. The World Bank: Updated income classifications. 2014. Retrieved on December 17, 2014 from: http:/data.worldbank.org/news/2015-country-classifications.

37. Centers for Disease Control and Prevention: State indicator report on physical activity. Atlanta, GA: US Department of Health and Human Services; 2014.

38. Moher D, Liberati A, Tetzlaff J, Altman DG, Group P: Preferred reporting items for systematic reviews and meta-analyses: the PRISMA statement. PLoS Med 2009, 6:e1000097.

39. Shea BJ, Grimshaw JM, Wells GA, Boers M, Andersson N, Hamel C, Porter AC, Tugwell P, Moher D, Bouter LM: Development of AMSTAR: a measurement tool to assess the methodological quality of systematic reviews. BMC Med Res Methodol 2007, 7:10.

40. Shea BJ, Hamel C, Wells GA, Bouter LM, Kristjansson E, Grimshaw J, Henry DA, Boers M: AMSTAR is a reliable and valid measurement tool to assess the methodological quality of systematic reviews. J Clin Epidemiol 2009, 62:1013-1020.

41. Mezzani A, Hamm LF, Jones AM, McBride PE, Moholdt T, Stone JA, Urhausen A, Williams MA: Aerobic exercise intensity assessment and prescription in cardiac rehabilitation: a joint position statement of the European Association for Cardiovascular Prevention and Rehabilitation, the American Association of Cardiovascular and Pulmonary Rehabilitation and the Canadian Association of Cardiac Rehabilitation. Eur J Prev Cardiol 2013, 20:442-467.

42. Tudor-Locke C, Sisson SB, Collova T, Lee SM, Swan PD: Pedometerdetermined step count guidelines for classifying walking intensity in a young ostensibly healthy population. Can J Appl Physiol 2005, 30:666-676.

43. Marshall SJ, Levy SS, Tudor-Locke CE, Kolkhorst FW, Wooten KM, Ji M, Macera CA, Ainsworth BE: Translating physical activity recommendations into a pedometer-based step goal: 3000 steps in 30 minutes. Am J Prev Med 2009, 36:410-415.

44. Garber CE, Blissmer B, Deschenes MR, Franklin BA, Lamonte MJ, Lee IM, Nieman DC, Swain DP, American College of Sports M: American College of Sports Medicine position stand. Quantity and quality of exercise for developing and maintaining cardiorespiratory, musculoskeletal, and neuromotor fitness in apparently healthy adults: guidance for prescribing exercise. Med Sci Sports Exerc 2011, 43:1334-1359.

45. Guyatt GH, Oxman AD, Vist GE, Kunz R, Falck-Ytter Y, Alonso-Coello P, Schunemann HJ: GRADE: an emerging consensus on rating quality of evidence and strength of recommendations. BMJ 2008, 336:924-926.

46. Downs SH, Black N: The feasibility of creating a checklist for the assessment of the methodological quality both of randomised and non-randomised studies of health care interventions. J Epidemiol Community Health 1998, 52:377-384.

47. The Cochrane Collaboration: Review manager (RevMan). The Nordic Cochrane Centre, The Cochrane Collaboration; 2012.

48. Brozek J, Oxman A, Schünemann H: GRADEpro. [Computer program]. Version 3.2 for Windows. 2008

49. Higgins JP, Thompson SG, Deeks JJ, Altman DG: Measuring inconsistency in meta-analyses. BMJ 2003, 327:557-560

50. Egger M, Davey Smith G, Schneider M, Minder C: Bias in meta-analysis detected by a simple, graphical test. BMJ 1997, 315:629-634.

doi:10.1186/2046-4053-3-147

Cite this article as: Reed et al:: Workplace physical activity interventions and moderate-to-vigorous intensity physical activity levels among working-age women: a systematic review protocol. Systematic Reviews 2014 3:147.

\section{Submit your next manuscript to BioMed Central and take full advantage of:}

- Convenient online submission

- Thorough peer review

- No space constraints or color figure charges

- Immediate publication on acceptance

- Inclusion in PubMed, CAS, Scopus and Google Scholar

- Research which is freely available for redistribution 